\title{
PERANAN PROGRAM PKPR (PELAYANAN KESEHATAN PEDULI REMAJA) TERHADAP KESEHATAN REPRODUKSI REMAJA DI KECAMATAN BULELENG
}

\author{
Ni Luh Kadek Alit Arsani ${ }^{1}$, Ni Nyoman Mestri Agustini ${ }^{2}$, I Ketut Indra Purnomo \\ ${ }^{1,3}$ Jurusan Ilmu Keolahragaan, ${ }^{2}$ Jurusan Pendidikan Jasmani Kesehatan dan Rekreasi \\ Fakultas Olahraga dan Kesehatan, Universitas Pendidikan Ganesha \\ Singaraja, Indonesia
}

e-mail: alit arsani@yahoo.com, mes3_dip@yahoo.co.id, asalkode@yahoo.co.id

\begin{abstract}
Abstrak
Tujuan penelitian ini adalah untuk mengetahui: 1) Peranan Puskesmas dalam Program Pelayanan Kesehatan Peduli Remaja (PKPR); 2) Keterlaksanaan program PKPR terhadap kesehatan reproduksi remaja; 3) Peranan program PKPR terhadap kesehatan reproduksi remaja. Penelitian ini merupakan penelitian deskriptif kualitatif dengan teknik pengumpulan data melalui wawancara, observasi, dan focus group discussion. Informan dipilih secara purposive sampling. Data dianalisis dengan menggunakan analisis interaktif model dari Miles dan Huberman terdiri dari empat tahap yaitu pengumpulan data, reduksi data, penyajian data, dan penarikan simpulan/verifikasi.

Hasil penelitian menunjukkan bahwa: 1) Peranan Puskesmas dalam program PKPR adalah sebagai ujung tombak pemberi pelayanan kesehatan di masyarakat termasuk remaja; 2) Program PKPR yang dicanangkan Puskesmas Buleleng 1 sebagian besar sudah terlaksana dengan baik, namun masih terdapat 1 sasaran yang belum tercapai yaitu pembentukan konselor sebaya serta belum maksimalnya sosialisasi kepada remaja secara luas; 3) PKPR dirasakan memiliki peranan yang sangat penting bagi remaja.
\end{abstract}

Kata kunci : kesehatan reproduksi, PKPR, remaja

\begin{abstract}
The aim of this study was to determine, 1) the role of community health centres (Puskesmas) in the health care services adolescent program, 2) the implementation of health care services adolescent programs on adolescent reproductive health, and 3) the role of health care services adolescent program on adolescent reproductive health. The method used in this study, is qualitative method, by interviews, observation, and focus group discussion. Informants selected by purposive sampling. Data were analyzed using interactive analysis model of Miles and Huberman consists of four stages: data collection, data reduction, data presentation, and conclusion /verification.

The results showed that: 1) The role of community health centers in health care services adolescent program (PKPR) is spearheading health providers in the community, including youth, 2) health care services adolescent program in community health centers (Puskesmas Buleleng 1) most have done well, but still there is one goal that has not been achieved, namely the formation of peer counselors and have maximum outreach to adolescents is widely; 3) perceived health care services adolescent program has a very important role for adolescents.
\end{abstract}

Key words: health care services adolescent program, reproductive health, adolescent. 


\section{PENDAHULUAN}

Masa remaja merupakan periode terjadinya pertumbuhan dan perkembangan yang terjadi secara dinamis dan pesat baik fisik, psikologis, intelektual, sosial, tingkah laku seksual yang dikaitkan dengan mulai terjadinya pubertas (Marcell, et. al., 2011). Masa ini adalah periode transisi dari masa kanak-kanak menuju dewasa. Pola karakteristik pesatnya tumbuh kembang ini menyebabkan remaja memiliki rasa keingintahuan yang besar, menyukai petualangan dan tantangan serta cenderung berani mengambil risiko tanpa pertimbangan yang matang (Soetjiningsih, 2004).

Data demografi menunjukkan bahwa remaja merupakan populasi yang besar dari penduduk dunia. Data WHO pada tahun 1995, sekitar seperlima penduduk dunia adalah remaja berumur 10-19 tahun. Penduduk Asia Pasifik merupakan $60 \%$ dari penduduk dunia, seperlimanya adalah remaja. Di Indonesia, data Biro Pusat Statistik (2009) kelompok umur 10-19 tahun adalah sekitar $22 \%$, yang terdiri dari $50,9 \%$ remaja laki-laki dan $49,1 \%$ remaja perempuan. Berdasarkan data Departemen Kesehatan (Depkes) Republik Indonesia tahun 2006, remaja Indonesia berjumlah sekitar 43 juta jiwa atau sekitar $20 \%$ dari jumlah penduduk. Ini sesuai dengan proporsi remaja di dunia, yaitu sekitar 1,2 miliar atau sekitar $1 / 5$ dari jumlah penduduk dunia. Pada tahun 2008, jumlah remaja di Indonesia diperkirakan sudah mencapai 62 juta jiwa. Hasil sensus pada tahun 2000 di Bali, menunjukkan proporsi remaja sebesar $26,29 \%$.

Banyaknya permasalahan dan krisis yang terjadi pada masa remaja menjadikan banyak ahli dalam bidang psikologi perkembangan menyebutnya sebagai masa krisis. Berbagai permasalahan yang terjadi pada remaja dipengaruhi oleh berbagai dimensi kehidupan dalam diri mereka, baik dimensi biologis, kognitif, moral dan psikologis serta pengaruh dari lingkungan sekitar. Saat ini hal yang menonjol pada remaja adalah dari sudut pandang kesehatan (Howard, et al., 2010). WHO (2003) menyebutkan semakin berkembangnya permasalahan kesehatan reproduksi remaja, yang menyangkut seks bebas, penyebaran penyakit kelamin, kehamilan di luar nikah atau kehamilan tidak diinginkan, aborsi, dan pernikahan usia muda. Secara umum di Bali, beberapa permasalahan remaja yang banyak disoroti saat ini antara lain adalah pergaulan bebas hingga pelecehan seksual yang berkaitan dengan kesehatan reproduksi remaja, perkelahian antar geng, penggunaan obat terlarang. Berdasarkan data Dinas Kesehatan Kabupaten Buleleng (2009), 10 prioritas kasus yang dihadapi remaja antara lain gangguan haid, sex pra nikah, kehamilan tidak diinginkan, dismenorhea, pacaran, infeksi menular seksual, Tuberkulosa, anemia, merokok, leukore. Salah satu permasalahan kesehatan remaja yang banyak disoroti saat ini adalah semakin meningkatnya angka kejadian HIV/AIDS pada remaja. Berdasarkan data Depkes pada tahun 2008 dan 2009, terjadi peningkatan yang signifikan pada rentangan usia muda, termasuk remaja. Di Bali, angka kejadian HIV/AIDS tercatat sebanyak 1615 kasus dan $50 \%$ dari jumlah tersebut adalah rentangan usia 19-25 tahun (Kompas, 2009). Angka kejadian HIV/AIDS di Kabupaten Buleleng pada tahun 2009 sudah menempati urutan kedua setelah Kota Madya Denpasar, yaitu sebanyak 650 kasus (anonim, 2006). Sebaran umur kejadian HIV/AIDS cukup mengejutkan karena peningkatan banyak terjadi pada kelompok umur muda (Anonim, 2007).

Salah satu upaya pemerintah dalam menangani permasalahan remaja adalah dengan pembentukan Program Pelayanan Kesehatan Peduli Remaja (PKPR). Program ini dapat dilaksanakan di Puskesmas, Rumah Sakit atau sentra-sentra dimana remaja berkumpul seperti mall (Depkes, 2005). Dalam pelaksanaan PKPR di Puskesmas, remaja diberikan pelayanan khusus melalui perlakuan khusus yang disesuaikan dengan keinginan, selera dan 
kebutuhan remaja. Secara khusus, tujuan dari program PKPR adalah meningkatkan penyediaan pelayanan kesehatan remaja yang berkualitas, meningkatkan pemanfaatan Puskesmas oleh remaja untuk mendapatkan pelayanan kesehatan, meningkatkan pengetahuan dan keterampilan remaja dalam pencegahan masalah kesehatan dan meningkatkan keterlibatan remaja dalam perencanaan, pelaksanaan dan evaluasi pelayanan kesehatan remaja. Adapun yang menjadi sasaran program ini adalah laki-laki dan perempuan usia 10-19 tahun dan belum menikah. Di Kabupaten Buleleng, program PKPR baru mulai dilaksanakan pada tahun 2007. Tidak semua Puskesmas di Buleleng melaksanakan program ini. Pelaksanaan program ini baru dirintis di Puskesmas Buleleng I.

Berdasarkan uraian tersebut di atas, terlihat bahwa permasalahan kesehatan remaja menjadi suatu hal yang sangat penting dan pelaksanaan PKPR menjadi salah satu jalan keluar permasalahan tersebut. Oleh sebab itu, perlu dilakukan kajian mengenai peranan PKPR terhadap kesehatan reproduksi remaja di Kecamatan Buleleng.

Penelitian sebelumnya yang berkaitan dengan masalah kesehatan reproduksi remaja adalah "Pengetahuan, Sikap dan Perilaku Remaja SMA terhadap Kesehatan Reproduksi di Kecamatan Buleleng Tahun 2010" (Doddy, dkk., 2010). Penelitian ini menunjukkan bahwa tingkat pengetahuan remaja SMA/SMK di Kecamatan Buleleng terhadap kesehatan reproduksi sebagian besar masih tergolong cukup dan kurang. Tingkat sikap siswa SMA/SMK terhadap kesehatan reproduksi di Kecamaatan Buleleng, Kabupaten Buleleng, secara umum memiliki sikap yang baik. Dan, tingkat perilaku siswa SMA/SMK terhadap kesehatan reproduksi di Kecamatan Buleleng, Kabupaten Buleleng, hampir separuh memiliki perilaku yang mengarah ke negatif.
Berdasarkan hasil penelitian ini, terlihat bahwa kondisi kesehatan reproduksi remaja di Buleleng masih perlu mendapatkan perhatian yang lebih. Salah satu perhatian yang diberikan oleh pemerintah adalah pelayanan dalam bentuk Program Kesehatan Peduli Remaja. Namun, keberadaan program ini belum sepenuhnya mendapatkan pemahaman dan penggunaan oleh remaja. Perlu dilakukan analsis mengenai kebutuhan remaja akan pelayanan kesehatan, penerimaan remaja terhadap program PKPR serta penggunaan PKPR oleh remaja.

Rumusan Masalah dalam penelitian ini adalah: 1) Bagaimanakah peranan Puskesmas dalam Program Pelayanan Kesehatan Peduli Remaja (PKPR)?; 2) Bagaimanakah keterlaksanaan Program Pelayanan Kesehatan Peduli Remaja (PKPR) terhadap kesehatan reproduksi remaja di Kecamatan Buleleng? 3) Bagaimanakah Peranan Program Pelayanan Kesehatan Peduli Remaja (PKPR) terhadap kesehatan reproduksi remaja?

Adapun tujuan penelitian ini adalah untuk mengetahui: 1) Peranan Puskesmas dalam Program Pelayanan Kesehatan Peduli Remaja (PKPR); 2) Keterlaksanaan program Pelayanan Kesehatan Peduli Remaja terhadap kesehatan reproduksi remaja (PKPR); 3) Peranan Program Pelayanan Kesehatan Peduli Remaja (PKPR) terhadap kesehatan reproduksi remaja. Sedangkan manfaat penelitian adalah: 1) Dapat menjadi acuan bagi pemerintah daerah, dalam hal ini Dinas Kesehatan dan jajarannya dalam memberikan pembinaan dan pelayanan kesehatan bagi remaja di kabupaten Buleleng; 2) Dapat menjadi referensi dalam perkuliahan IImu Kesehatan Fakultas Olahraga dan Kesehatan Undiksha. Selain itu, juga dapat menjadi referensi dalam pembinaan remaja di Bali pada khususnya dan memberikan sumbangan pemikiran terhadap khasanah ilmu tentang kesehatan reproduksi remaja secara umum. 


\section{METODE}

Penelitian ini dilakukan di Wilayah kerja Puskesmas Buleleng I, Kecamatan Buleleng. Penelitian ini menggunakan metode penelitian kualitatif. Strategi penelitian adalah studi kasus terpancang tunggal. Sumber data terdiri dari: 1) Informan; 2) Tempat dan peristiwa; 3) Dokumen. Informan dipilih secara purposive sampling yaitu peneliti memilih sumber yang mengetahui tentang program PKPR di Puskesmas Buleleng I, yaitu kepala Puskesmas, staf/petugas Puskesmas di bagian PKPR, dan remaja di Kecamatan Buleleng. (Sugiyono, 2010)

Langkah paling awal adalah menyiapkan pedoman wawancara, FGD, dan observasi sebagai alat bantu dalam pengumpulan data. Kemudian dilanjutkan dengan penelitian dengan proses pengumpulan data, reduksi data, sajian data dan penarikan kesimpulan. Dari kesimpulan yang didapatkan kemudian dilakukan interpretasi. Dengan mengikuti proses penelitian ini, maka luaran penelitian yang didapat adalah deskripsi konsep peranan program PKPR terhadap kesehatan reproduksi remaja di Kecamatan Buleleng.

Deskripsi yang dihasilkan, akan digunakan selanjutnya oleh peneliti (dosen) sebagai dasar untuk pengabdian masyarakat. Tujuan dari pengabdian masyarakat tersebut adalah pembinaan remaja khususnya pada kesehatan reproduksinya.

Teknik pengumpulan data dengan menggunakan wawancara, focus group discussion (FGD), observasi, dan dokumen. Wawancara dilakukan terhadap informan Kepala Puskesmas, pemegang program PKPR, remaja yang mengalami permasalahan kesehatan reproduksi (tercatat di pelaporan Puskesmas) serta remaja di wilayah kerja Puskesmas Buleleng 1 yang dipilih secara purposive sampling. Wawancara dilakukan dengan berpedoman pada pedoman wawancara. Permasalahan yang hendak dipecahkan melalui wawancara ini adalah peranan Puskesmas dan keterlaksanaan program PKPR selama ini.

FGD dilakukan sekali dengan peserta Kepala Puskesmas, pemegang program PKPR, remaja yang mengalami permasalahan kesehatan reproduksi (tercatat di pelaporan Puskesmas) serta remaja di wilayah kerja Puskesmas Buleleng 1 yang dipilih secara purposive sampling. Permasalahan yang hendak dipecahkan melalui wawancara ini adalah peranan Puskesmas dalam prevensi (pencegahan) dan mengatasi masalah kesehatan reproduksi remaja serta keterlaksanaan program PKPR selama ini.

Observasi dilakukan oleh peneliti terhadap kegiatan yang dilakukan dalam pelaksanaan program kesehatan peduli remaja yang dilakukan baik di dalam Puskesmas maupun di luar Puskesmas. Permasalahan yang hendak dipecahkan melalui observasi ini adalah pelaksanaan program yang sedang terlaksana saat ini baik yang di dalam maupun di luar Puskesmas.

Pengumpulan data melalui dokumen dilakukan oleh peneliti dengan pencatatan data-data yang terdapat dalam dokumen PKPR, baik mengenai permasalahan remaja yang terjadi, program yang dicanangkan serta pelaksanaan program peduli remaja yang sudah dilakukan. Uji keterpercayaan data dilakukan melalui: 1) Uji validitas melalui triangulasi teori, data, metode dan peneliti; 2) Uji reliabilitas melalui perpanjangan pengamatan dan member check.

Teknik analisis data menggunakan Analisis Interaktive model dari Miles dan Huberman terdiri dari empat tahap yaitu pengumpulan data, reduksi data, penyajian data dan penarikan simpulan/verifikasi. Langkah pertama adalah mengumpulkan data di lapangan. Data yang diperoleh di lapangan cukup banyak, sehingga perlu direduksi (merangkum, memilih hal-hal yang pokok, memfokuskan pada hal-hal yang penting dan membuang data yang tidak perlu). Setelah data direduksi, kemudian 
data disajikan, kemudian diambil kesimpulan untuk memperoleh gambaran tentang topik penelitan. (Sugiyono, 2010)

\section{HASIL DAN PEMBAHASAN}

Puskesmas sebagai pusat pengembangan kesehatan masyarakat yang juga membina peran serta masyarakat disamping memberikan pelayanan kesehatan secara menyeluruh dan terpadu kepada masyarakat di wilayah kerjanya dalam bentuk kegiatan pokok. Salah satu tugas Puskesmas melayani remaja yang merupakan bagian dari masyarakat. Puskesmas Buleleng 1 merupakan salah satu Puskesmas yang berada di Kabupaten Buleleng, memiliki wilayah kerja 15 kelurahan dan 1 desa. Berdasarkan data tahun 2012, jumlah penduduk yang berada di wilayah kerja Puskesmas Buleleng 1 adalah sebanyak 57785 orang. Adapun dari jumlah tersebut, sebanyak 8999 orang $(16 \%)$ adalah penduduk dalam usia remaja. Salah satu bentuk perhatian pemerintah terhadap kesehatan remaja terlihat dari dicanangkannya pembentukan PKPR di tingkat Puskesmas pada tahun 2003 yang diadopsi dari WHO (World Health Organization). Prinsip dari PKPR yang dicanangkan tersebut adalah dapat terakses oleh semua golongan remaja, layak, dapat diterima, efektif, dan efisien.

Berdasarkan wawancara, observasi, dan dokumentasi yang telah dilakukan, ditemukan bahwa Puskesmas Buleleng 1 merupakan Puskesmas pertama di Buleleng yang melaksanakan program PKPR. Penunjukkan tersebut dilakukan langsung oleh Dinas Kesehatan Provinsi Bali dengan pertimbangan Puskesmas Buleleng 1 merupakan Puskesmas di Kabupaten Buelelng yang terletak di tengah kota dan dianggap paling siap untuk melakukan program tersebut. Berbagai tindak lanjut dilakukan oleh Puskesmas setelah penunjukkan sebagai pelaksana Program PKPR.

Adapun tindak lanjut tersebut dimulai dari penunjukkan staf Puskesmas
Buleleng 1 sebagai pemegang program PKPR, penyusunan program kerja PKPR serta penyediaan sarana prasarana yang diperlukan dalam pelaksanaan kegiatan PKPR. Staf Puskesmas Buleleng 1 yang ditunjuk sebagai pemegang program PKPR adalah Ibu Ni Luh Padmini. Untuk tempat pelayanan PKPR telah disediakan ruangan khusus bagi konseling remaja sehingga memberikan ruang yang bersifat privasi. Pelaksanaan program PKPR tidak hanya dijalankan oleh pemegang program saja, tetapi tentunya memerlukan kerja sama dengan staf/bagian lainnya. Adapun staf/bagian lain di Puskesmas yang diikutsertakan dalam program PKPR antara lain program UKS (Usaha Kesehatan Sekolah), program PKM (Pendidikan Kesehatan Masyarakat), program kesehatan gigi, program KIA/KB (Kesehatan ibu dan anak/Keluarga berencana), pelayanan poliklinik khususnya pelayanan IMS (infeksi menular seksual) dan HIV/AIDS, pelayanan laboratorium dan P2M (Pencegahan penyakit menular). Dengan adanya kerja sama lintas bagian ini, diharapkan dapat menunjang keterlaksanaan dan kelancaran kegiatan program PKPR. Pengawasan terhadap pelaksanaan program PKPR di Puskesmas Buleleng 1 senantiasa dilakukan secara rutin. Dinas Kesehatan baik tingkat provinsi maupun kabupaten selaku dinas yang membawahi Puskesmas melakukan supervisi berupa kunjungan rutin tiap akhir tahun untuk mengontrol keterlaksanaan program selama setahun.

Berdasarkan wawancara dengan Kepala Puskesmas Buleleng 1 serta observasi terhadap dokumen, Program PKPR di Puskesmas Buleleng 1 sudah dimulai sejak tahun 2008 dengan didahului pemasangan plang sebagai Puskesmas Peduli Remaja. Staf yang ditunjuk sebagai penanggung jawab program PKPR adalah ibu $\mathrm{Ni}$ Luh Padmini (perawat). selain memiliki pendidikan sebagai perawat, ibu $\mathrm{Ni}$ Luh Padmini juga memiliki pendidikan di bidang konseling (Sarjana Bimbingan Konseling). Staf tersebut telah mendapatkan 
pelatihan sebelumnya sebanyak 3 kali, yaitu 1) Tahun 2008 di Denpasar di PPKTK Provinsi Bali berupa pelatihan konseling remaja; 2) Tahun 2009 di Jakarta berupa pelatihan penanganan kecanduan NAPZA dan 3) Tahun 2011 di Bogor berupa pelatihan konselor sebaya. Adapun program kegiatan yang menjadi tugas PKPR antara lain: 1) Pemberian informasi dan edukasi; 3) Pelayanan klinis medis termasuk pemeriksaan penunjang dan rujukannya; 3 ) Konseling; 4) Pendidikan keterampilan hidup sehat (PKHS); 5) Pelatihan konselor sebaya; 6) Pelayanan rujukan sosial dan pranata hukum.

Berdasarkan wawancara dengan pemegang program PKPR, dari 6 program kegiatan yang dicanangkan tersebut, program yang sudah terlaksana hingga saat ini adalah: 1) Penyuluhan dan pemberian $\mathrm{KIE}$; 2) Pelayanan klinis medis termasuk pemeriksaan penunjang dan rujukannya; 3 ) Konseling; 4) Pelatihan KKR dalam bentuk pendidikan keterampilan hidup sehat 5) Pelayanan rujukan dan pengambilan darah VCT. Program yang belum terlaksana adalah kegiatan pembentukan konselor sebaya. Ketidakterlaksanaan pembentukan konselor sebaya ini disebabkan oleh adanya program yang tumpang tindih dengan KPA dan KB.

Sasaran dari program PKPR di Puskesmas ini yaitu remaja yang berusia 10 hingga 24 tahun baik sehat maupun sakit, individu ataupun kelompok, dalam bentuk penyuluhan ataupun pelayanan kesehatan di dalam maupun di luar gedung. Pencapaian target sasaran sudah hampir terlaksana semua, baik berupa konseling ke Puskesmas (2 hingga 3 orang tiap bulan), kunjungan ke sekolah (pada bulan Agustus, September, dan Oktober). Namun, berdasarkan wawancara dan focus group discussion remaja ditemukan bahwa penyampaian informasi mengenai keberadaan dan pelayanan PKPR belum mencakup seluruh remaja di wilayah kerja Puskesmas Buleleng I. Kurangnya pengetahuan remaja mengenai keberadaan
PKPR ini berdampak pada tidak maksimalnya pelayanan, konseling dan penyuluhan mengenai kesehatan remaja. Adapun kendala yang ditemui adalah kondisi tenaga pelaksana, waktu dan biaya tidak sesuai dengan cakupan wilayah kerja Puskesmas, sehingga masih ada daerah yang belum mendapatkan pelayanan ini. Evaluasi terhadap pencapaian target atau keberhasilan program adalah melalui laporan bulanan dan laporan semester, cakupan pasien di VCT, pembentukan konselor remaja, pelaksanaan penyuluhan ke sekolah-sekolah tiap tahun ajaran baru.

Pelayanan Kesehatan Peduli

Remaja (PKPR) merupakan pelayanan kesehatan yang ditujukan dan dapat dijangkau oleh remaja, menyenangkan, menerima remaja dengan tangan terbuka, menghargai remaja, menjaga kerahasiaan, peka akan kebutuhan terkait dengan kesehatannya serta efektif dan efesien dalam memenuhi kebutuhan tersebut. Berdasarkan wawancara dan focus group discussion remaja di Buleleng, ditemukan bahwa keberadaan program PKPR di Puskesmas Buleleng 1 belum sepenuhnya diketahui oleh remaja. Remaja yang mengetahui keberadaan program ini mendapatkan informasi di Puskesmas saat melakukan pemeriksaan secara langsung ataupun di sekolah melalui penyuluhan yang dilakukan oleh Puskesmas (staf program PKPR) ke sekolah saat penerimaan siswa baru, pembinaan PMR (Palang Merah Remaja) di sekolah serta saat remaja (siswa) tersebut mengikuti persiapan lomba KKR.

Berdasarkan observasi dokumen yang terdapat di tempat konseling PKPR, berbagai interaksi pernah dilakukan oleh remaja yang datang. Data kunjungan ke PKPR, tiap harinya terapat sekitar 2 hingga 3 kunjungan. Kunjungan tesebut beragam, mulai dari konseling, pelayanan kesehatan (pemeriksaan dan pengobatan) hingga pelayanan rujukan. Sejak Januari 2012, sudah terdapat 14 orang yang dirujuk untuk pemeriksaan VCT. 
Data tersebut didukung oleh hasil focus group discussion yang dilakukan, dimana ditemukan adanya interaksi remaja berupa konseling, pelayanan kesehatan dan pengobatan kasus infeksi menular seksual (IMS). Dari FGD remaja, didapatkan adanya antusias yang tinggi dari remaja agar program PKPR ini senantiasa selalu diperkenalkan ke remaja sekolah hingga remaja pada umumnya terutama remaja yang tinggal di daerah yang jauh dari lokasi Puskesmas Buleleng Dari masukan remaja, beberapa bentuk pengenalan program PKPR dapat dilakukan melalui penyampaian informasi baik secara langsung maupun tidak langsung. Beberapa bentuk pengenalan yang menurut para remaja dapat dilakukan oleh pihak terkait antara lain: 1) Melalui sekeha teruna teruni yang ada di masing-masing banjar; 2) Pemberian pamphlet atau selebaran yang berisikan informasi mengenai adanya PKPR yang memberikan pelayanan khusus bagi remaja; 3) Website yang dapat diakses oleh remaja secara bebas; 4) Penyuluhan ke sekolahsekolah; Melalui iklan di radio. Penyampaian informasi itupun tidak harus selalu langsung dari Puskesmas, namun dapat dilakukan secara estafet oleh para remaja sehingga dapat mengurangi beban kerja petugas kesehatan.

Berbagai manfaat yang dirasakan oleh remaja dari adanya program PKPR ini adalah: 1) Mendapatkan informasi yang benar mengenai kesehatan remaja; 2) Mendapatkan informasi mengenai cara menjaga kesehatan reproduksi; 3) Tempat berkonsultasi mengenai berbagai permasalahan remaja sehingga tidak terjerumus ke hal yang negative; 4) Sebagai tempat berbagi dengan remaja lain khususnya mengenai kesehatan; 5) Teman dan pengalaman di bidang kesehatan remaja bertambah.

Dalam program PKPR ini diharapkan agar selalu ada tindak lanjut atau follow up baik dari petugas kesehatan ataupun pihak lain terhadap kegiatan-kegiatan yang sudah terlaksana. Berdasarkan wawancara terhadap remaja yang sudah pernah melakukan konseling dalam program ini, menyebutkan agar pelayanan yang diberikan di PKPR memiliki kelanjutan sehingga permasalahan yang dihadapi oleh remaja bisa terselesaikan dengan tuntas.

Di Indonesia, unit penanggungjawab penyelenggaraan upaya kesehatan untuk jenjang tingkat pertama adalah Puskesmas. Pada saat ini puskesmas telah didirikan di hampir seluruh pelosok tanah air. Berdasarkan Keputusan Menteri Kesehatan Tahun 2004, disebutkan bahwa fungsi dari Puskesmas antara lain sebagai pusat penggerak pembangunan berwawasan kesehatan, pusat pemberdayaan masyarakat, dan pusat pelayanan kesehatan strata pertama baik perorangan maupun masyarakat.

Puskesmas sebagai pemberi pelayanan kesehatan terdepan di masyarakat mempunyai peran yang sangat strategis dalam upaya peningkatan taraf kesehatan masyarakat, termasuk remaja. Berbagai permasalahan pada remaja saat ini semakin berkembang luas, sehingga memerlukan perhatian lebih. Salah satu program yang dicanangkan oleh pemerintah adalah dengan pembentukan program Pelayanan Kesehatan Peduli Remaja (PKPR). Pelayanan Kesehatan Peduli Remaja (PKPR) merupakan pelayanan kesehatan yang ditujukan dan dapat dijangkau oleh remaja, menyenangkan, menerima remaja dengan tangan terbuka, menghargai remaja, menjaga kerahasiaan, peka akan kebutuhan terkait dengan kesehatannya serta efektif dan efesien dalam memenuhi kebutuhan tersebut (DepKes RI, 2005). Program ini seharusnya menjadi prioritas utama dalam pengembangan program kerja Puskesmas mengingat kesesuaiannya dengan permasalahan yang semakin banyak dihadapi remaja.

Puskesmas sebagai pelaksana program PKPR memiliki peranan yang sangat besar terhadap keberlangsungan program tersebut. Masuknya program PKPR dalam 
program Puskesmas merupakan awal dari peranan Puskesmas. Penunjukan staf sebagai pemegang program PKPR sebagai langkah selanjutnya. Dengan demikian terdapat staf Puskesmas yang memang khusus mendalami dan menangani kegiatan-kegiatan yang terkait dengan remaja. Mengingat kegiatan program PKPR ini sangat luas, maka tentunya tidak dapat diselesaikan hanya oleh pemegang program saja. Oleh sebab itu, penunjukan staf tersebut juga diikuti dengan penunjukan bagian lain di Puskesmas untuk senantiasa bekerja sama dengan program ini dalam menyelesaikan tugasnya. Bagian lain tersebut meliputi program UKS (Usaha Kesehatan Sekolah), program PKM (Pendidikan Kesehatan Masyarakat), program kesehatan gigi, program KIA/KB (Kesehatan ibu dan anak/Keluarga berencana), pelayanan poliklinik khususnya pelayanan IMS (infeksi menular seksual) dan HIV/AIDS, pelayanan laboratorium, dan P2M (Pencegahan penyakit menular).

Berdasarkan Pedoman PKPR di Puskesmas (DepKes RI, 2005), tugas yang diemban oleh program PKPR ini cukup luas, mencakup 1) Pemberian informasi dan edukasi; 2) Pelayanan klinis medis termasuk pemeriksaan penunjang dan rujukannya; 3 ) Konseling; 4) Pendidikan keterampilan hidup sehat (PKHS); 5) Pelatihan konselor sebaya; 6) Pelayanan rujukan sosial dan pranata hukum. Adapun pelaksanaan kegiatan tersebut disesuaikan dengan kondisi dan kebutuhannya, dilaksanakan di dalam gedung atau di luar gedung, untuk sasaran perorangan atau kelompok, dilaksanakan oleh petugas Puskesmas atau petugas lain di institusi atau masyarakat berdasarkan kemitraan.

Berdasarkan hasil penelitian, didapatkan bahwa dari keenam tugas PKPR tersebut, terdapat satu tugas yang belum terlaksana yaitu pelatihan konselor sebaya. Tidak terealisasinya kegiatan ini terkait dengan tumpang tindihnya kegiatan pelatihan konselor yang dilaksanakan oleh Komisi Pemberantasan AIDS (KPA)
Buleleng. selain itu, pelaksanaan kegiatan lainnya seperti pemberian informasi dan edukasi, pendidikan kesehatan, pelayanan klinis dan rujukan serta konseling dirasakan masih belum menjangkau seluruh remaja.

Adapun yang menjadi kendala adalah keterbatasan tenaga, waktu dan biaya. Tenaga pelaksana kegiatan PKPR hingga saat ini masih diemban oleh 1 orang petugas sehingga tidak bisa menjangkau seluruh remaja di wilayah kerja Puskesmas Buleleng 1 yang meliputi 15 kelurahan dan 1 desa. Melihat luasnya cakupan wilayah kerja Puskesmas hendaknya petugas yang bertanggung jawab dalam program PKPR tidak hanya 1 orang dengan juga didukung oleh staf di program lain seperti staf program UKS (Usaha Kesehatan Sekolah), program PKM (Pendidikan Kesehatan Masyarakat), program kesehatan gigi, program $\mathrm{KIA} / \mathrm{KB}$ (Kesehatan ibu dan anak/Keluarga berencana), pelayanan poliklinik khususnya pelayanan IMS (infeksi menular seksual) dan HIV/AIDS, pelayanan laboratorium dan P2M (Pencegahan penyakit menular).

$$
\text { Program PKPR memiliki }
$$

karakteristik karakteristik dari PKPR, yaitu kebijakan, prosedur, petugas, fasilitas yang peduli remaja, keterlibatan remaja dan masyarakat, berbasis masyarakat serta pelayanan yang komprehensif, efektif dan efisien. Oleh sebab itu, PKPR sebagai penyedia pelayanan kesehatan yang khusus bagi remaja dirasakan sangat bermanfaat bagi remaja. Adapun berdasarkan hasil penelitian, didapatkan manfaat tersebut mencakup informasi mengenai kesehatan dan cara menjaganya, tempat berkonsultasi hingga sebagai tempat berbagi dengan remaja lainnya. Besarnya manfaat PKPR bagi remaja ini menunjukkan tingginya kebutuhan remaja akan pelayanan kesehatan yang memang difokuskan bagi mereka, mengingat perbedaan situasi dan kondisi pada masa remaja. Berbagai kegiatan yang ditawarkan dalam PKPR senantiasa sesuai dengan harapan remaja serta dapat diterima dengan baik. 


\section{SIMPULAN DAN SARAN}

Berdasarkan hasil dan pembahasan tersebut di atas, maka dapat ditarik beberapa simpulan sebagai berikut: 1) Peranan Puskesmas dalam program PKPR adalah sebagai ujung tombak pemberi pelayanan kesehatan di masyarakat termasuk remaja. Puskesmas sebagai penyedia sarana dan prasarana program PKPR agar program tersebut dapat terlaksana sesuai dengan sasaran; 2) Program PKPR yang dicanangkan Puskesmas Buleleng 1 sebagian besar sudah terlaksana dengan baik, namun masih terdapat 1 sasaran yang belum tercapai yaitu pembentukan konselor sebaya serta belum maksimalnya sosialisasi kepada remaja secara luas; 3) PKPR dirasakan memiliki peranan yang sangat penting bagi remaja. Melalui PKPR ini remaja dapat memperoleh pengetahuan mengenai kesehatan, tempat bersosialisasi, hingga mendapatkan pelayanan kesehatan yang memperhatikan kebutuhan remaja.

Adapun saran yang dapat diberikan antara lain: 1) Peranan Puskesmas dalam program PKPR adalah sebagai ujung tombak pemberi pelayanan kesehatan di masyarakat termasuk remaja, karena itu akan sangat baik apabila program PKPR terdapat di setiap puskesmas, sehingga dapat menjangkau pelayanan yang lebih luas kepada remaja; 2) Perlu dilakukan sosialisasi yang lebih luas terhadap keterlaksanaan program PKPR kepada para remaja melalui sosialisasi ke sekolahsekolah, sekeha taruna-teruni, pemberian pamphlet atau selebaran yang berisikan informasi mengenai adanya PKPR yang memberikan pelayanan khusus bagi remaja; 3) Untuk tercapainya keterlaksanaan program PKPR dengan baik diperlukan adanya sokongan dana yang memadai dari pemerintah selaku pemegang kebijakan.

\section{DAFTAR PUSTAKA}

Anonim. 2006. Penduduk, Ketenagakerjaan, Pendidikan dan Kesehatan. Available at: http://www.bkkbn.go.id.
Anonim. 2007. Strategi Penanggulangan HIV dan AIDS 2007-2010. Komisi Penanggulangan AIDS. Jakarta.

Badan Pusat Statistik. 2009. Data Statistik Indonesia. Available at: http:// spiritia.or.id/Stats/StatCurr.pdf

Dinas Kesehatan Kabupaten Buleleng. 2009. Laporan Tahunan Program Kesehatan Lanjut Usia dan Program Kesehatan Remaja Tahun 2009. Buleleng.

Direktorat Kesehatan Keluarga, Dirjen Bina Kesehatan Masyarakat, Depkes RI. 2005. Pedoman Pelayanan Kesehatan Peduli Remaja di Puskesmas. Jakarta.

Doddy T, Mestri A, Kusuma W, 2010. Pengetahuan, Sikap dan Perilaku Remaja SMA terhadap Kesehatan Reproduksi di Kecamatan Buleleng Tahun 2010.

Howard, T.L., Marcell, A.V., Plowden, K., Watson, C. 2010. Exploring Women's Perceptions About Their Role in Supporting Partners' and Sons' Reproductive Health Care. Americans Journal of Mens's Health; 4: 297-304.

Kompas. 11 Februari 2009. Kasus AIDS di Bali Makin Mengkhawatirkan. Available at: http://kesehatan.kompas.com.

Marcell, A.V., Wibbelsman, C., Seigel, W.M. 2011. Male Adolescent Sexual and Reproductive Health Care. Pediatrics; 128: $1658-1678$.

Soetjiningsih. 2004. Tumbuh Kembang Remaja dan Permasalahannya. Jakarta: EGC.

Sugiyono. 2010. Memahami Penelitian Kualitatif. Bandung: Alfabeta.

WHO. 2003. Adolescent Friendly Health Service, An Agenda for Change. 